\title{
Randomized controlled trial of pegbovigrastim as an adjunct therapy for naturally occurring severe clinical mastitis cases in dairy cows
}

\author{
J. Denis-Robichaud, ${ }^{1} \oplus$ M. Christophe, ${ }^{2}$ J.-P. Roy, ${ }^{2} \oplus$ S. Buczinski, ${ }^{2} \oplus$ M. Rousseau, ${ }^{2} \odot$ \\ M. Villettaz Robichaud, ${ }^{2} \odot$ and J. Dubuc ${ }^{2 *} \odot$
}

\section{Graphical Abstract}

\section{Effect of pegbovigrastim (PEG) as an adjunct therapy for naturally} occurring severe clinical mastitis cases in dairy cows.

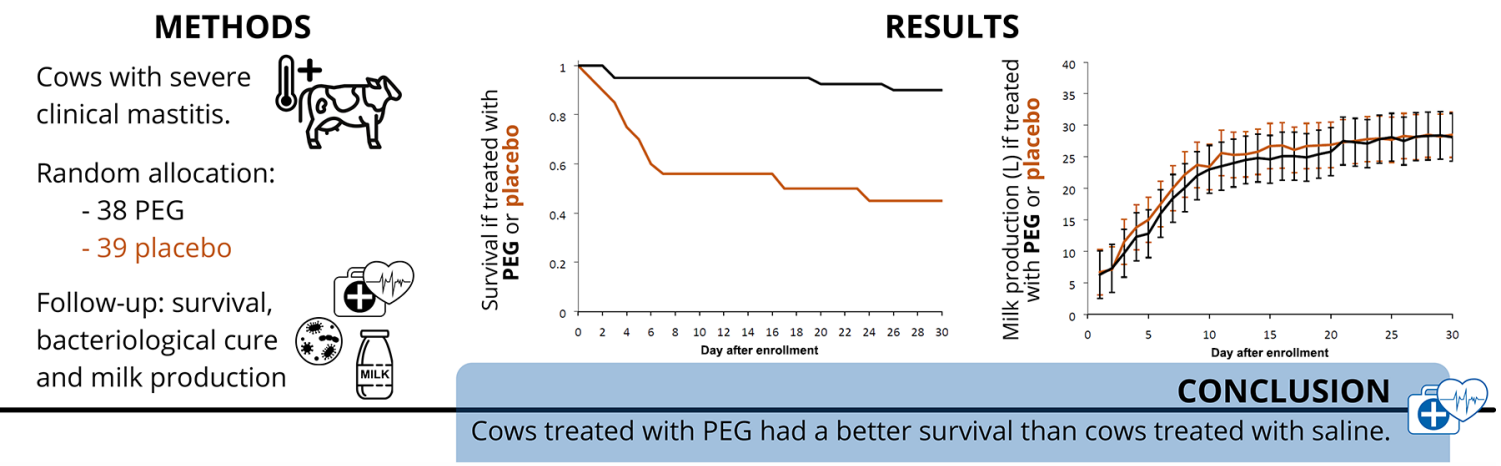

\section{Summary}

The main objective of this controlled randomized trial was to quantify the impact of pegbovigrastim as an adjunct therapy for severe clinical mastitis cases in dairy cows. A total of 77 cows were enrolled in the study. Cows treated with pegbovigrastim had an improved survival ( $30 \mathrm{~d}$ after treatment) compared with cows that received saline (control), but the treatment had no effect on bacteriological cure at $14 \mathrm{~d}$ post-treatment or on daily milk production during the 30-d period following enrollment. These findings improve our understanding of the effect of pegbovigrastim as an adjunct treatment on survival and health in severe mastitis cases in cows.

\section{Highlights}

- Treatment with pegbovigrastim increased survival after a case of severe clinical mastitis.

- Treatment with pegbovigrastim had no effect on subsequent bacteriological cure.

- Treatment with pegbovigrastim had no effect on subsequent milk production.

\footnotetext{
${ }^{1}$ Independent researcher, Amqui, Québec, Canada, G5J 2N5, ${ }^{2}$ Département de sciences cliniques, Faculté de médecine vétérinaire, Université de Montréal, 3200, rue Sicotte, St-Hyacinthe, QC, Canada, J2S 2M2. *Corresponding author: jocelyn.dubuc@umontreal.ca. @ 2021, The Authors. Published by Elsevier Inc. and Fass Inc. on behalf of the American Dairy Science Association ${ }^{\oplus}$. This is an open access article under the CC BY license (http://creativecommons.org/ licenses/by/4.0/). Received June 07, 2021. Accepted June 28, 2021.
} 


\title{
Randomized controlled trial of pegbovigrastim as an adjunct therapy for naturally occurring severe clinical mastitis cases in dairy cows
}

\author{
J. Denis-Robichaud, ${ }^{1} \odot$ M. Christophe, ${ }^{2}$ J.-P. Roy, ${ }^{2} \odot$ S. Buczinski, ${ }^{2} \odot$ M. Rousseau, ${ }^{2} \odot$ \\ M. Villettaz Robichaud, ${ }^{2} \odot$ and J. Dubuc ${ }^{2 *} \odot$
}

\begin{abstract}
The main objective of this study was to quantify the effect of pegbovigrastim (PEG) as an adjunct therapy for naturally occurring severe mastitis cases on survival, intramammary bacteriological cure, and subsequent milk production. A double-blinded, randomized controlled trial was conducted on a single commercial dairy farm. During the study period, all cows having a case of severe clinical mastitis, defined as the presence of abnormal milk and inflammation in one quarter or more combined with the presence of systemic signs (pyrexia, dehydration, or recumbency), were enrolled in the study. In addition to a standardized therapy combining systemic and intramammary antimicrobials as well as systemic anti-inflammatory drugs, cows received a subcutaneous injection of either $2.7 \mathrm{~mL}$ of $0.9 \%$ sterile saline (control group; CON) or $2.7 \mathrm{~mL}$ of PEG (PEG group). A milk sample for bacteriological analysis was taken before treatment was administered and a second sample was taken $14 \mathrm{~d}$ after enrollment. Survival (30 d post-treatment) and bacteriological cure (14 d post-treatment) were analyzed by survival analysis and chi-squared tests, respectively, whereas daily milk production was treated as a repeated measure in mixed regression models. The 77 cows enrolled in the study were of parity 2 to 4 (mean $=3$ ) and between 3 and $302 \mathrm{~d}$ in milk (mean =154). The bacteria identified in milk at enrollment were Klebsiella $\mathrm{spp} .(\mathrm{n}=48 ; 62 \%)$, Escherichia coli $(\mathrm{n}=16$; $21 \%)$, Enterobacter spp. $(\mathrm{n}=10 ; 13 \%)$, or no growth $(\mathrm{n}=3 ; 4 \%)$. The probability of survival during the first $30 \mathrm{~d}$ after treatment was higher in the PEG group (84\%) than in the control group (46\%). Daily milk production over the 30 -d period following treatment and bacteriological cure $14 \mathrm{~d}$ post-treatment did not differ between groups. Overall, cows treated with PEG as an adjunct therapy for naturally occurring cases of severe clinical mastitis had a better survival than cows treated with saline.
\end{abstract}

I ntramammary infections are a major economic burden for dairy producers. Clinical mastitis events result in direct and indirect costs due mainly to increased culling, milk yield reduction, milk discard, and treatment (Rollin et al., 2015; Aghamohammadi et al., 2018). Severe clinical mastitis, defined as abnormal milk, abnormal udder, and systemic signs of illness, also takes its toll on dairy farms, with up to $15 \%$ of cases resulting in death of the affected cow (Erskine et al., 2002; Pinzón-Sánchez and Ruegg, 2011; Ruegg, 2012).

Pegbovigrastim (PEG) is the polyethylene glycolated form (covalently bound) of bovine granulocyte colony-stimulating factor, a growth factor targeting hematopoietic progenitor cells, stimulating production and differentiation of neutrophils, and it was developed to improve immunity of dairy cows during the transition period (Hassfurther et al., 2015). In Canada, PEG (Imrestor, Elanco) is labeled for the reduction in incidence of clinical mastitis in the first $30 \mathrm{~d}$ of lactation in periparturient dairy cows and replacement heifers. In this context, 2 doses of PEG need to be administered: the first $1 \mathrm{wk}$ before the expected due date and the second within $24 \mathrm{~h}$ after calving. Recent studies showed that such use of PEG increased circulating neutrophils around parturition (Kimura et al., 2014; van Schyndel et al., 2018). It was also associated with decreased odds of clinical mastitis during the first $30 \mathrm{~d}$ of lactation compared with untreated cows (Hassfurther et al., 2015; Canning et al., 2017; Ruiz et al., 2017), but there was no diminution in the odds of severe mastitis, perhaps due to the low incidence observed in the study (0.2\%; Ruiz et al., 2017). As stated on the Canadian label, the current use of PEG is preventative. Although prevention is of utmost importance, cases of clinical mastitis are still happening on dairy farms, with a reported herd incidence rate varying widely, from 1 to 97 cases per 100 cow-years (Olde Riekerink et al., 2008). Furthermore, 5 to $14 \%$ of clinical mastitis cases have been reported to be severe (Erskine et al., 2002; Pinzón-Sánchez and Ruegg, 2011; Ruegg, 2012).

During a clinical mastitis case, PMN are recruited rapidly in the mammary gland; they represent the most effective defense against bacterial infection when they ingest pathogens by phagocytosis (Paape et al., 2002). While multiple biological elements are in play to control IMI and inflammation, increased recruitment of neutrophils could mitigate mortality and improve the bacteriological cure and subsequent milk production of affected cows, especially in severe mastitis cases. Thus, the use of PEG as an adjunct therapy in these cases could improve the survival and performance of cows.

The main objective of this study was to quantify the effect of PEG as an adjunct therapy on survival, intramammary bacteriological cure, and subsequent milk production in cows with naturally occurring severe mastitis. The hypothesis was that PEG would improve survival in the $30 \mathrm{~d}$ after treatment, bacteriological cure

\footnotetext{
${ }^{1}$ Independent researcher, Amqui, Québec, Canada, G5J 2N5, ${ }^{2}$ Département de sciences cliniques, Faculté de médecine vétérinaire, Université de Montréal, 3200, rue Sicotte, St-Hyacinthe, QC, Canada, J2S 2M2. *Corresponding author: jocelyn.dubuc@umontreal.ca. @ 2021, The Authors. Published by Elsevier Inc. and Fass Inc. on behalf of the American Dairy Science Association ${ }^{\oplus}$. This is an open access article under the CC BY license (http://creativecommons.org/ licenses/by/4.0/). Received June 07, 2021. Accepted June 28, 2021.
} 
$14 \mathrm{~d}$ post-treatment, and milk production in the $30 \mathrm{~d}$ following treatment.

This double-blinded randomized controlled trial (cow level) was approved by the Animal Care Committee of the Université de Montréal (\#18-Rech-1985), and the REFLECT statement was used to report the findings (O'Connor et al., 2010). The trial was conducted between July 2018 and April 2021 in a single herd of 300 lactating Holstein cows (QC, Canada) in which cows were housed in a freestall facility and fed a TMR. This herd was selected by convenience based on being located within $1 \mathrm{~h}$ of the bovine ambulatory clinic of the Faculté de médecine vétérinaire of the Université de Montréal (St-Hyacinthe, QC, Canada), on having a high incidence of naturally occurring cases of severe clinical mastitis [lactational incidence risk of $11.3 \%$ between June 2017 and June 2018; 94\% (gram-negative bacteria) and 6\% (no growth) were identified using the on-farm Tri-Plate culture system (University of Minnesota) during that period], for not already using PEG on the farm, and for being willing to participate in the present study. Severe clinical mastitis was defined as the presence of abnormal milk and inflammation in one quarter or more, combined with systemic signs of illness (pyrexia, dehydration, or recumbency; Pinzón-Sánchez and Ruegg, 2011). This definition was standardized for farm staff before and during data collection. The farm manager was in charge of the identification, sampling, and treatment of cases of severe clinical mastitis.

A sample size of 77 cows ( 35 cows per treatment group $+10 \%$ loss to follow-up) was targeted for this study based on 3 different sample size estimations following results of a pilot study. The first (20 cows per treatment group) was based on finding a difference in the proportion of cows surviving the first week following the mastitis case (50\% in the control group vs. $90 \%$ in the PEG group), with $95 \%$ confidence and $80 \%$ power (Dohoo et al., 2009). The second (20 cows per treatment group) was based on finding a difference in the proportion of cows having bacteriological cure $14 \mathrm{~d}$ after enrollment $(10 \%$ in the control group vs. $50 \%$ in the PEG group), with $95 \%$ confidence and $80 \%$ power. The third (23 cows per treatment group) was based on finding a significant difference in milk production of $5 \mathrm{~kg} / \mathrm{d}(25 \mathrm{~kg}$ in the control group and $30 \mathrm{~kg}$ in the PEG group) considering a variance of 36 with $95 \%$ confidence and $80 \%$ power.

When a case of severe clinical mastitis was diagnosed on the farm, the cow was enrolled in the study. At enrollment, all cows were assigned randomly to 1 of 2 treatment groups: (1) control group (CON; subcutaneous injection of $2.7 \mathrm{~mL}$ of $0.9 \%$ sterile saline) or (2) PEG group (subcutaneous injection of $2.7 \mathrm{~mL}$ of PEG; Imrestor, Elanco). The syringes were numbered (1 to 77) before the start of the study and assigned randomly using a random number generator (Excel spreadsheet; Microsoft Corp.) to contain saline or PEG (balanced within groups of 10 syringes); this procedure was carried out by a technician not involved in farm data collection. The syringes from both groups were identical and could not be differentiated on the farm. Farmers were blinded to treatment allocation. The syringes were refrigerated at $4^{\circ} \mathrm{C}$ until use. At enrollment, rectal body temperature was taken using a thermometer. A milk sample from the affected quarter was taken aseptically by the herd manager from all cows. All samples were kept on ice until arrival at the bovine ambulatory clinic (within $6 \mathrm{~h}$ ).
Once milk was taken, cows were administered a subcutaneous injection in the neck using the prepared syringes (saline or PEG) following the preassigned numerical order (1 to 77). At the same time, all cows received a standardized therapy made of $16 \mathrm{mg} / \mathrm{kg}$ trimethoprim-sulfamide IM (Borgal; Merck Animal Health) twice daily for $5 \mathrm{~d}, 0.5 \mathrm{mg} / \mathrm{kg}$ of meloxicam IV (Metacam; Boehringer Ingelheim) once at enrollment, intramammary ceftiofur (Spectramast LC; Zoetis) in the affected quarter once daily for $2 \mathrm{~d}$, and $2 \mathrm{~L}$ of homemade $7.5 \%$ hypertonic saline solution IV once at enrollment. Ad libitum fresh water was offered to all treated cows after receiving the hypertonic saline solution.

On d 14, a second milk sample from the affected quarter was collected aseptically from all cows. Parity and DIM were obtained from farm records, and culling or death dates, as well as the daily milk production of all enrolled cows, were recorded for $30 \mathrm{~d}$ by farm staff (from milking parlor data; DairyPlan C21).

All milk samples were aseptically collected after the teat end was swabbed with gauze soaked in $70 \%$ methanol, immediately placed on ice, and sent to the veterinary diagnostic laboratory of the Université de Montréal (St-Hyacinthe, QC, Canada) for standard bacteriological analysis. Briefly, a volume of $10 \mu \mathrm{L}$ from the milk sample was cultured on Columbia blood agar $(5 \%$ sheep blood) and the remaining sample was incubated. Cultures were read after $16 \mathrm{~h}$ of incubation; if negative, the incubated milk sample was plated on Columbia blood agar and the primary cultures re-incubated for $24 \mathrm{~h}$. Milk samples with growth of $\geq 3$ bacterial species were considered contaminated. Cultures with $\geq 1 \mathrm{cfu}$ at $48 \mathrm{~h}$ were considered positive. Colonies were counted (cfu/mL) and identified using MALDI-TOF MS technology. One colony from each bacterial species was transferred to the MALDI target plate (Bruker Daltonics), overlaid with $0.7 \mu \mathrm{L}$ of $70 \%$ formic acid, and allowed to dry. One microliter of matrix solution ( $\alpha$-cyano-4hydroxycinnamic acid in 50\% acetonitrile and $2.5 \%$ trifluoroacetic acid) was then applied to each spot and allowed to dry. Plates were run on a Microflex LT/SH mass spectrometer (Bruker Daltonics). Generated spectra were compared with spectra from the RUO Biotyper database (Bruker Daltonics) and assigned a score based on similarity. When the primary culture yielded no bacterial growth even after $48 \mathrm{~h}$ of incubation, the culture from the incubated milk sample was read. Bacteriological cure was defined as the absence $14 \mathrm{~d}$ later of the bacteria identified at enrollment.

Statistical analyses were conducted using $\mathrm{R}$ version 4.0.0 (R Core Team, 2015). Median, mean, minimum, and maximum were used to describe continuous data, and proportions were used to describe categorical data. Cows were categorized according to their lactation stage (early: $<75$ DIM, mid: 75-174 DIM, and late: $\geq 175$ DIM). Parity, lactation stage, DIM, rectal temperature, and identified bacteria in milk at enrollment were compared between cows from the control and PEG groups using a Wilcoxon rank sum test for continuous data and a chi-squared test for categorical data. The treatment's associations with bacteriological cure at $\mathrm{d} 14$ were assessed using a chi-squared test (stats package; R Core Team, 2015). The association between treatment and daily milk production during the $30 \mathrm{~d}$ following the mastitis event was assessed using Satterthwaite's method ANOVA for repeated measures in a mixed linear regression model (lmer; lme4 package in R), adjusting for DIM as a fixed effect and for the cow as a random effect). Death 
Table 1. Descriptive statistics of bacteriology results (cfu/mL) at enrollment and $\mathrm{d} 14$ from 77 cows with severe clinical mastitis enrolled in a randomized double-blinded controlled trial, treated either with pegbovigrastim (PEG) as an adjunct therapy or with saline (CON)

\begin{tabular}{|c|c|c|c|c|c|}
\hline \multirow[b]{2}{*}{ Bacteriology } & \multirow[b]{2}{*}{ Statistic $^{1}$} & \multicolumn{2}{|c|}{ Enrollment $(n=77)$} & \multicolumn{2}{|c|}{ Day $14(n=58)$} \\
\hline & & $\begin{array}{c}\text { PEG } \\
(n=38)\end{array}$ & $\begin{array}{c}\text { CON } \\
(n=39)\end{array}$ & $\begin{array}{c}\text { PEG } \\
(n=36)\end{array}$ & $\begin{array}{c}\text { CON } \\
(n=22)\end{array}$ \\
\hline Klebsiella spp. & Minimum & 900 & 700 & 100 & 500 \\
\hline $\mathrm{n}_{\text {enrollment }}=48$ & Q1 & 1,500 & 1,200 & 1,200 & 1,900 \\
\hline \multirow[t]{3}{*}{$\mathrm{n}_{\mathrm{d} 14}=22$} & Median & 5,000 & 5,000 & 1,500 & 2,800 \\
\hline & Q3 & 5,000 & 5,000 & 2,200 & 3,000 \\
\hline & Maximum & 5,000 & 5,000 & 3,000 & 5,000 \\
\hline Escherichia coli & Minimum & 800 & 1,000 & $N A^{2}$ & NA \\
\hline $\mathrm{n}_{\text {enrollment }}=16$ & Q1 & 2,000 & 2,200 & & \\
\hline \multirow[t]{3}{*}{$\mathrm{n}_{\mathrm{d} 14}=0$} & Median & 5,000 & 5,000 & & \\
\hline & Q3 & 5,000 & 5,000 & & \\
\hline & Maximum & 5,000 & 5,000 & & \\
\hline Enterobacter spp. & Minimum & 1,100 & 1,300 & 700 & 1,200 \\
\hline $\mathrm{n}_{\text {enrollment }}=10$ & Q1 & 1,800 & 1,600 & 700 & 1,200 \\
\hline \multirow[t]{3}{*}{$\mathrm{n}_{\mathrm{d} 14}=3$} & Median & 4,000 & 4,500 & 700 & 1,200 \\
\hline & Q3 & 5,000 & 5,000 & 700 & 1,700 \\
\hline & Maximum & 5,000 & 5,000 & 700 & 1,700 \\
\hline
\end{tabular}

${ }^{1} \mathrm{Q} 1, \mathrm{Q} 3=$ first and third quartiles, respectively.

${ }^{2}$ Not applicable.

or culling in the month following treatment was assessed using the log-rank test and the Kaplan-Meier estimator (survival package in R). Dead or culled cows were treated as loss to follow-up and were not included in analysis after their removal from the herd. Statistical significance was considered if $P \leq 0.05$.

A total of 77 cows were enrolled in the study (39 in CON; 38 in PEG). No adverse events were noted during the study. Cows enrolled in the study were of parity 2 to 4 (median $=3$; mean $=$ 3 ) and between 3 and 302 DIM (median $=148$; mean $=154$ ) at enrollment. Nineteen cows were in early lactation (10 in CON: 3 to 62 DIM; 9 in PEG: 15 to 50 DIM), 27 were in mid lactation (12 in CON: 125 to 154 DIM; 15 in PEG: 81 to 171 DIM), and 31 were in late lactation (17 in CON: 189 to 257 DIM; 14 in PEG: 201 to 286 DIM). Their body temperature at enrollment was between 38.0 and $41.0^{\circ} \mathrm{C}$ (median $=39.7^{\circ} \mathrm{C}$ ), and the bacteria identified in milk at enrollment were Klebsiella spp. $(\mathrm{n}=48 ; 62 \%)$, Escherichia coli $(\mathrm{n}$ $=16 ; 21 \%)$, Enterobacter spp. $(\mathrm{n}=10 ; 13 \%)$ or no growth $(\mathrm{n}=3$; $4 \%$ ). At d 14, a total of 25 cows (PEG: $n=13$; CON: $n=12$ ) were found with bacteria in their milk, which were identified as Klebsiella spp. $(\mathrm{n}=22 ; 88 \%)$, E. coli $(\mathrm{n}=0 ; 0 \%)$, and Enterobacter spp. $(\mathrm{n}=3 ; 12 \%)$. All identified bacteria at enrollment and $\mathrm{d} 14$ were pure growth (no mixed bacteria) at levels $\geq 100 \mathrm{cfu} / \mathrm{mL}$. Descriptive statistics of the identified bacteria are presented in Table 1. None of the population characteristics differed between the CON and PEG groups (parity: $P=0.62$; DIM: $P=0.83$; lactation stage: $P=0.68$; body temperature at enrollment: $P=0.77$; proportion of bacteria in milk at enrollment: $P=0.77)$. Nineteen cows $(25 \%)$ died in the first week post-treatment (16 had Klebsiella spp.; 3 had E. coli) and 5 $(6 \%)$ more died or were culled between 7 and $30 \mathrm{~d}$ after enrollment (3 had Klebsiella spp; 2 had E. coli). The probability of surviving during the first $30 \mathrm{~d}$ following treatment was higher in the PEG group than in the control group [PEG: $34 / 38 ; 89 \%$, CON: $19 / 39$; $49 \%$; odds ratio $(\mathrm{OR})_{\mathrm{PEG}: \mathrm{CON}}=5.3 ; P<0.01$; Figure 1$]$. Of cows that survived until d 14 after enrollment, there was no difference in the proportion of bacteriological cure at $\mathrm{d} 14$ between the PEG and control groups (PEG: 25/36; 69\%, CON: 10/22; 45\%; OR PEG:CON $=2.4 ; P=0.12)$. Similarly, the daily milk production of the cows that survived $(\mathrm{n}=53)$ did not differ between the control and PEG groups over the 30-d period following enrollment $\left(P_{\text {treatment }}=0.72\right.$; $P_{\text {treatment } \times \text { day }}=0.99$; Figure 2).

Although many studies have looked at the use of PEG for the prevention of mastitis (Hassfurther et al., 2015; Canning et al., 2017; Ruiz et al., 2017) or the treatment of chronic mastitis (Putz et al., 2019), much remains unknown about its use as an adjunct therapy for the treatment of bovine diseases such as naturally oc-

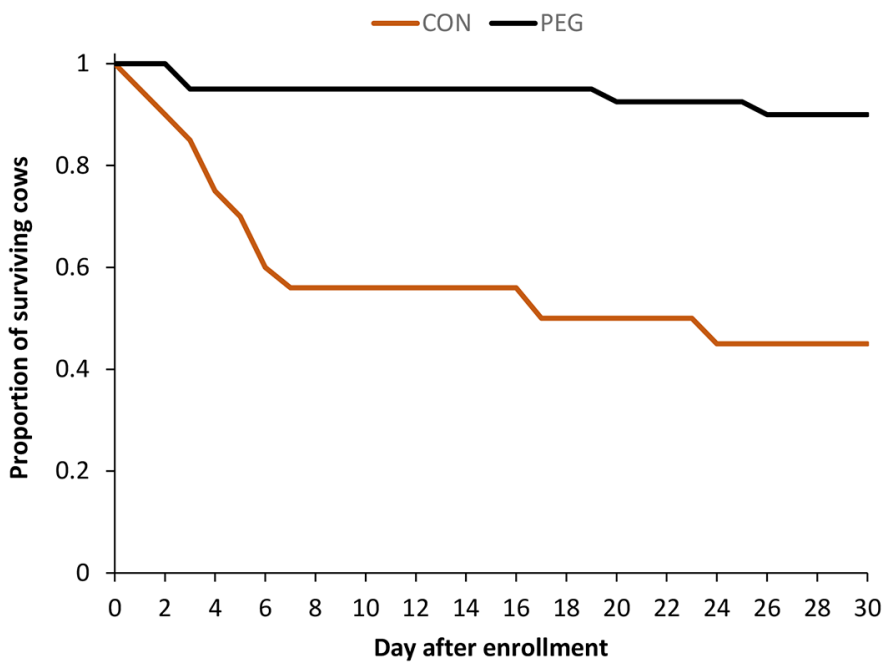

Figure 1. Survival $( \pm 95 \% \mathrm{Cl})$ plotted using Kaplan-Meier estimator of 77 cows with severe clinical mastitis enrolled in a randomized double-blinded controlled trial, treated either with pegbovigrastim (PEG; $n=38$; black line) as an adjunct therapy or with saline (CON; $n=39$; gray line). Nonsurvival was when cows died or were culled. 


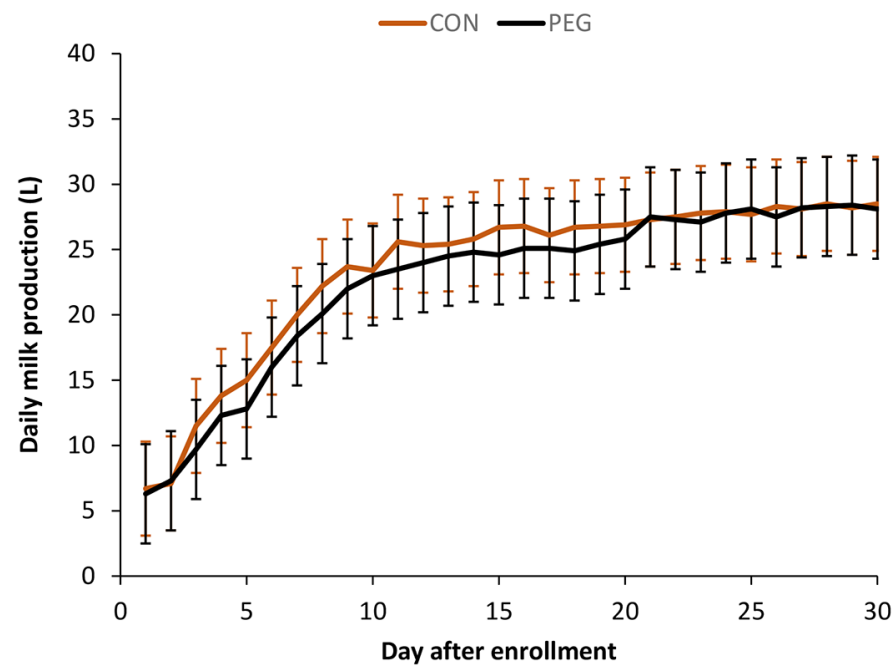

Figure 2. Daily milk production (marginal means $\pm 95 \% \mathrm{Cl}$ ) of 58 cows with severe clinical mastitis enrolled in a randomized double-blinded controlled trial, treated either with pegbovigrastim (PEG; $n=36$ ) or with saline (CON; $n$ $=22$ ) as an adjunct therapy. The marginal means were obtained from a mixed linear regression model using Satterthwaite's method ANOVA for repeated measures and adjusted for DIM as a fixed effect.

curring severe clinical mastitis (Kehrli et al., 1991). The use of PEG in the present study resulted in better odds of survival during the $30 \mathrm{~d}$ following the mastitis event compared with saline (control group). There were, however, no differences in the odds of bacteriological cure on d 14 post-treatment or in daily milk production over the 30-d period after treatment.

The cows enrolled in the present study were all from one farm, and the bacteria identified in milk at mastitis diagnosis were all coliforms, mainly Klebsiella spp., with 3 cultures being negative. This is line with the fact that naturally occurring severe clinical mastitis is often caused by coliforms, which may cause a release of LPS endotoxins that results in an acute phase response (Ruegg, 2012). The present results suggest that inferences from the current study might be limited to a population of severe clinical mastitis cases caused by coliforms. Moreover, the high proportion of Klebsiella found in this study differs from that in other studies (Gröhn et al., 2004; Ruegg, 2012), suggesting that variability among farms likely limits the external validity of the present results. With an overall proportion of clinical mastitis cases caused by coliforms reported to be between 12 and 40\% (Ruegg, 2012), it would be interesting to assess whether the use of PEG would also improve the short-term prognosis (survival), and perhaps other survival and health parameters when other pathogens are involved.

The current results show that when surviving, cows treated with PEG as an adjunct therapy did not have increased odds of bacteriological cure at $\mathrm{d}$ 14. It is unclear whether the numerical difference in bacteriological cure observed between the PEG and control groups was not statistically significant due to the absence of association or to the limited sample size (lack of statistical power). Based on the difference in bacteriological cure found in the present study, we would have needed 79 cows per treatment group to show a significant statistical difference. Unfortunately, it was not possible to enroll such a large number of cows in the context of the current study. It is also possible that the single milk sample taken to assess bacteriological cure was insufficient and resulted in misclassification bias (Dohoo et al., 2011). It is important to keep in mind that bacteriological cure in cases of severe clinical mastitis caused by coliforms is generally high (Lago et al., 2011) unless the IMI becomes chronic, which can be the case with Klebsiella spp. Future studies could use a parallel interpretation of duplicate or consecutive day samples, which has been shown to improve the sensitivity of bacterial culture for CNS and Streptococcus spp. (Dohoo et al., 2011). It is unclear, however, how it would affect the identification of gram-negative pathogens following a severe mastitis case.

As reported in other studies, the preventive use of PEG in the prepartum period did not result in improved subsequent milk production or decreased culling rates over the whole lactation (Kimura et al., 2014; Hassfurther et al., 2015; Ruiz et al., 2017). As the follow-up period in the present study was only $30 \mathrm{~d}$, it is unclear how milk production and survival would have evolved for cows in each treatment group. For example, milk production has been shown to be reduced for up to $70 \mathrm{~d}$ following Klebsiella and E. coli mastitis (Gröhn et al., 2004). Although the present findings suggest a limited long-term effect of using PEG as an adjunct therapy for severe clinical mastitis, more studies are necessary to confirm this. Future studies should also consider collecting SCC data.

The present study found that the use of PEG as an adjunct therapy in cases of naturally occurring severe clinical mastitis resulted in better survival ( $30 \mathrm{~d}$ after enrollment). No effects of treatment on bacteriological cure $14 \mathrm{~d}$ post-treatment or on daily milk production during the 30 -d period following enrollment were found. These findings should be considered by veterinarians and dairy producers wanting to improve the short-term survival of cows with severe clinical mastitis.

\section{References}

Aghamohammadi, M., D. Haine, D. F. Kelton, H. W. Barkema, H. Hogeveen, G. P. Keefe, and S. Dufour. 2018. Herd-level mastitis-associated costs on Canadian dairy farms. Front. Vet. Sci. 5:100. https://doi.org/10.3389/fvets .2018 .00100 .

Canning, P., R. Hassfurther, T. TerHune, K. Rogers, S. Abbott, and D. Kolb. 2017. Efficacy and clinical safety of pegbovigrastim for preventing naturally occurring clinical mastitis in periparturient primiparous and multiparous cows on US commercial dairies. J. Dairy Sci. 100:6504-6515. https:/ /doi.org/10.3168/jds.2017-12583.

Dohoo, I. R., S. Andersen, R. Dingwell, K. Hand, D. Kelton, K. Leslie, Y. Schukken, and S. Godden. 2011. Diagnosing intramammary infections: Comparison of multiple versus single quarter milk samples for the identification of intramammary infections in lactating dairy cows. J. Dairy Sci. 94:5515-5522. https://doi.org/10.3168/jds.2011-4486.

Dohoo, I. R., S. W. Martin, and H. Stryhn. 2009. Veterinary Epidemiologic Research. VER Inc.

Erskine, R. J., P. C. Bartlett, J. L. VanLente, and C. R. Phipps. 2002. Efficacy of systemic ceftiofur as a therapy for severe clinical mastitis in dairy cattle. J. Dairy Sci. 85:2571-2575. https://doi.org/10.3168/jds.S0022 -0302(02)74340-3.

Gröhn, Y. T., D. J. Wilson, R. N. González, J. A. Hertl, H. Schulte, G. Bennett, and Y. H. Schukken. 2004. Effect of pathogen-specific clinical mastitis on milk yield in dairy cows. J. Dairy Sci. 87:3358-3374. https://doi.org/10 .3168/jds.S0022-0302(04)73472-4.

Hassfurther, R. L., T. N. TerHune, and P. C. Canning. 2015. Efficacy of polyethylene glycol-conjugated bovine granulocyte colony-stimulating factor for reducing the incidence of naturally occurring clinical mastitis in periparturient dairy cows and heifers. Am. J. Vet. Res. 76:231-238. https://doi .org/10.2460/ajvr.76.3.231. 
Kehrli, M. E. Jr., J. S. Cullor, and S. C. Nickerson. 1991. Immunobiology of hematopoietic colony-stimulating factors: Potential application to disease prevention in the bovine. J. Dairy Sci. 74:4399-4412. https://doi.org/10 .3168/jds.S0022-0302(91)78636-0.

Kimura, K., J. P. Goff, P. Canning, C. Wang, and J. A. Roth. 2014. Effect of recombinant bovine granulocyte colony-stimulating factor covalently bound to polyethylene glycol injection on neutrophil number and function in periparturient dairy cows. J. Dairy Sci. 97:4842-4851. https://doi.org/10 $.3168 /$ jds.2013-7242.

Lago, A., S. M. Godden, R. Bey, P. L. Ruegg, and K. Leslie. 2011. The selective treatment of clinical mastitis based on on-farm culture results: I. Effects on antibiotic use, milk withholding time, and short-term clinical and bacteriological outcomes. J. Dairy Sci. 94:4441-4456. https://doi.org/10.3168/jds 2010-4046.

O’Connor, A. M., J. M. Sargeant, I. A. Gardner, J. S. Dickson, M. E. Torrence, C. E. Dewey, I. R. Dohoo, R. B. Evans, J. T. Gray, M. Greiner, G. Keefe, S. L. Lefebvre, P. S. Morley, A. Ramirez, W. Sischo, D. R. Smith, K. Snedeker, J. Sofos, M. P. Ward, and R. Wills. 2010. The REFLECT statement: Methods and processes of creating reporting guidelines for randomized controlled trials for livestock and food safety. J. Vet. Intern. Med. 24:57-64. https:// doi.org/10.1111/j.1939-1676.2009.0441.x.

Olde Riekerink, R. G. M., H. W. Barkema, D. F. Kelton, and D. T. Scholl. 2008. Incidence rate of clinical mastitis on Canadian dairy farms. J. Dairy Sci. 91:1366-1377. https://doi.org/10.3168/jds.2007-0757.

Paape, M., J. Mehrzad, X. Zhao, J. Detilleux, and C. Burvenich. 2002. Defense of the bovine mammary gland by polymorphonuclear neutrophil leukocytes. J. Mammary Gland Biol. Neoplasia 7:109-121. https://doi.org/10 .1023/A:1020343717817.

Pinzón-Sánchez, C., and P. L. Ruegg. 2011. Risk factors associated with shortterm post-treatment outcomes of clinical mastitis. J. Dairy Sci. 94:33973410. https://doi.org/10.3168/jds.2010-3925.

Putz, E. J., J. M. Eder, T. A. Reinhardt, R. E. Sacco, E. Casas, and J. D. Lippolis. 2019. Differential phenotype of immune cells in blood and milk following pegylated granulocyte colony-stimulating factor therapy during a chronic Staphylococcus aureus infection in lactating Holsteins. J. Dairy Sci. 102:9268-9284. https://doi.org/10.3168/jds.2019-16448.
R Core Team. 2015. A Language and Environment for Statistical Computing. Foundation for Statistical Computing. R Core Team, Vienna, Austria.

Rollin, E., K. C. Dhuyvetter, and M. W. Overton. 2015. The cost of clinical mastitis in the first 30 days of lactation: An economic modeling tool. Prev. Vet. Med. 122:257-264. https://doi.org/10.1016/j.prevetmed.2015.11.006.

Ruegg, P. L. 2012. New perspectives in udder health management. Vet. Clin. North Am. Food Anim. Pract. 28:149-163. https://doi.org/10.1016/j.cvfa .2012.03.001

Ruiz, R., L. O. Tedeschi, and A. Sepúlveda. 2017. Investigation of the effect of pegbovigrastim on some periparturient immune disorders and performance in Mexican dairy herds. J. Dairy Sci. 100:3305-3317. https://doi.org/10 .3168/jds.2016-12003.

Van Schyndel, S. J. V., J. Carrier, O. B. Pascottini, and S. J. LeBlanc. 2018. The effect of pegbovigrastim on circulating neutrophil count in dairy cattle: A randomized controlled trial. PLoS One 13:e0198701. https://doi.org/10 .1371/journal.pone.0198701.

\section{Notes}

J. Denis-Robichaud (10 https://orcid.org/0000-0002-7742-0631

J.-P. Roy (1) https://orcid.org/0000-0002-0444-2303

S. Buczinski (1) https://orcid.org/0000-0002-8460-4885

M. Rousseau () https://orcid.org/0000-0002-2702-434X

M. Villettaz Robichaud (D) https://orcid.org/0000-0001-9685-1827

J. Dubuc () https://orcid.org/0000-0003-1013-8372

Partial financial support for this study was provided by the "Fonds du Centenaire" of the Faculté de médecine vétérinaire of the Université de Montréal (St-Hyacinthe, QC, Canada).

The authors greatly acknowledge the technical support provided by Raphaël Beauchemin (Ferme JN Beauchemin, St-Ours, QC, Canada) and Jean-Philippe Pelletier (St-Hyacinthe, QC, Canada).

The authors have not stated any conflicts of interest. 